\title{
EFFECT OF COMPLEX FORMATION ON ELECTROCHEMICAL BEHAVIOUR OF METAL-CONTAINING WASTE WATERS
}

\author{
Olga Covaliova \\ Research Centre of Applied and Ecological Chemistry of the State University of Moldova \\ 60, Mateevici Street, MD 2009, Chisinau, Moldova \\ Email: olga196cov@yahoo.com, phone: (373 22) 577707
}

\begin{abstract}
The problem of preventing the heavy metals and other toxic substances release in environment due to the discharges of untreated plating and rinsing solutions is actual from both ecologic and economic point of view. It is crucial to prevent the environmental pollution and uncontrolled losses of resources (metals and other substances). The treatment technologies used today are not always efficient and cost saving and in some cases they may even provoke the secondary pollution of environment. Electrochemical treatment of industrial waste waters is one of the most promising technologies as it implies the same principles as the main technological processes and does not require introducing of chemicals into the treated solution. However, until now this method was given insufficient attention, although there are certain publications in this field [1].

The electrochemical behaviour of some $d$-metal complexes was studied and discussed from the viewpoint of water treatment requirements. The studies performed in the model plating solutions of $\mathrm{Zn}, \mathrm{Ni}, \mathrm{Cu}$ ammonia and pyrophosphate complexes, polynuclear $\mathrm{Cr}$ complexes have shown that the application of conventional reagent waste water treatment methods for such solutions would be inefficient. Examination of potentio-dynamic polarization curves registered in studied solutions have shown, that due to the formation of series of $\mathrm{Zn}$ ammonia complexes, alkaline treatment will not ensure $\mathrm{Zn}$ removal from such solutions, and application of electrocoagulation treatment method will not be efficient enough. It was also found that in case of $\mathrm{Ni}$-, $\mathrm{Cr}$ containing solutions electrochemical treatment can be used for $\mathrm{Cu}$ removal, whereas for the effective $\mathrm{Cr}(\mathrm{VI})$ removal the electrocoagulation would be required, which entails the redox processes resulted in the formation of hydroxides. The research has shown that the approach on the heavy metal removal from the used plating solutions may be different depending on the plating bath composition.
\end{abstract}

Keywords: electrochemical processes, model plating solutions, ligands, complex salts, polarization curves.

\section{Introduction}

The presence of metal complex salts, specifically of $\mathrm{Zn}(\mathrm{II}), \mathrm{Cr}(\mathrm{III})$ and $\mathrm{Cr}(\mathrm{VI}), \mathrm{Ni}(\mathrm{II}), \mathrm{Cu}(\mathrm{II})$, etc. in the plating solutions play an important role in electrochemical processes of heavy metal removal from them. There are numerous works in the field of plating processes, in which the influence of complex salts on the cathode processes is studied only from the point of view of the quality of cathode coatings formed [2-6]. However, cathode processes in the low-concentrated model waste water solutions were practically paid no attention. Therefore, the special research in this field was undertaken by us. Taking into account that the most broadly distributed ligands in plating industry are ammonia salts, pyrophosphate-, citrate-, tartrate-ions, organic amines and others, which are coordination-active with regard to the metal ions, this research was focused on the study of the specifics of cathode processes in the presence of some of the mentioned ligands.

The above listed metals possess amphoteric properties, and in alkaline solutions they can form hydroxide complexes of $\left[\mathrm{Me}(\mathrm{OH})_{n}\right]^{(z-n)}$ type. So, the chemical (alkaline) treatment of waste waters containing these metals will be inefficient. In the presence of ligands, metal hydroxides participate in complex formation reactions, which can be schematically presented as follows:

$$
\begin{aligned}
& \mathrm{Me}(\mathrm{OH})_{\mathrm{z} \downarrow}+\mathrm{nNH}_{3} \rightarrow\left[\mathrm{Me}\left(\mathrm{NH}_{3}\right)_{\mathrm{n}}\right]^{7+}+\mathrm{z} \mathrm{OH}^{-} \\
& \mathrm{Me}(\mathrm{OH})_{\mathrm{z} \downarrow}+\mathrm{nP}_{2} \mathrm{O}_{7}{ }^{4-} \rightarrow\left[\mathrm{Me}\left(\mathrm{P}_{2} \mathrm{O}_{7}\right)_{\mathrm{n}}\right]^{\mathrm{z}-4 \mathrm{n}}+\mathrm{z} \mathrm{OH}^{-} \\
& \mathrm{Me}(\mathrm{OH})_{\mathrm{z} \downarrow}+\mathrm{nCit}^{3-} \rightarrow\left[\mathrm{Me}(\mathrm{Cit})_{n}\right]^{7-3 \mathrm{n}}+\mathrm{z} \mathrm{OH}^{-} \\
& \mathrm{Me}(\mathrm{OH})_{\mathrm{z} \downarrow}+\mathrm{nTart}^{2-} \rightarrow\left[\mathrm{Me}(\mathrm{Tart})_{\mathrm{n}} \mathrm{z}^{\mathrm{z}-2 \mathrm{n}}+\mathrm{z} \mathrm{OH}^{-}\right. \\
& \mathrm{Me}(\mathrm{OH})_{\mathrm{z} \downarrow}+\mathrm{nOx}^{2-} \rightarrow\left[\mathrm{Me}(\mathrm{Ox})_{\mathrm{n}}\right]^{-2 \mathrm{2n}}+\mathrm{z} \mathrm{OH}^{-} \\
& \mathrm{Me}(\mathrm{OH})_{\mathrm{z} \downarrow}+\mathrm{nH}_{2} \mathrm{NR} \rightarrow\left[\mathrm{Me}\left(\mathrm{H}_{2} \mathrm{NR}\right)_{\mathrm{n}}\right]^{\mathrm{z}+}+\mathrm{z} \mathrm{OH}^{-}
\end{aligned}
$$

As the function of water $\mathrm{pH}$, the number of coordinated ligands $(n)$ can be widely varied, and this brings out certain difficulties in the data interpretation for electrolytic processes. The various standpoints were expressed with regard to the mechanisms of such processes. Thus, in [7] it is supposed that, in spite of the exclusively low concentration of free metal ions in ligand-containing solutions, the discharge of simple cations occurs on cathode. In favour of such mechanism, the authors suggest that the accelerated dissociation of complex ions proceeds within the double electric layer. However, this concept has not been experimentally proved so far. The other assumption is related to the direct discharge of complex 
ions on cathode. As far back as in the mid 50-ies of XXth century, A.N. Frumkin with team [8], based on the theory of delayed discharge, have explained this by the effect of repulsing action of negative charge, due to the anions deforming in double electric field and their dipole orientation. According to the third point of view, metal is deposited on cathode as a result of the secondary process.

With the scope to improve the existing methods of electrochemical treatment of low-concentrated waste waters and make them more efficient, we studied the behaviour of ammonia and pyrophosphate complexes in diluted model plating solutions.

\section{Materials and Methods}

The effect of complex forming substances (ligands) concentration on complex composition and distribution was studied in solutions where the ratio metal ions : ligands concentrations was varied from 1:1 to 1:10. Standard behaviour of ligands during the complex formation was taken into account. Thus, ammonium salts in solutions with the $\mathrm{pH}$ increase to the alkaline area can produce ammonia, following the well-known scheme:

$$
\mathrm{NH}_{4}^{+}+\mathrm{OH}^{-} \rightleftarrows \mathrm{NH}_{3}+\mathrm{H}_{2} \mathrm{O}
$$

Ammonia molecules thus formed can participate in complex formation with heavy metal ions which make part of metal aquacomplexes in water solutions, substituting a number of coordinated water molecules, following the scheme:

$$
\left[\mathrm{Me}\left(\mathrm{H}_{2} \mathrm{O}\right)_{\mathrm{n}}\right]^{\mathrm{z}} \cdot \mathrm{mNH}_{3} \longleftrightarrow\left[\mathrm{Me}\left(\mathrm{NH}_{3}\right)_{\mathrm{m}}\left(\mathrm{H}_{2} \mathrm{O}\right)_{\mathrm{n}-\mathrm{m}}\right]^{\mathrm{z+}}+\mathrm{mH}_{2} \mathrm{O}
$$

It is known that the coordination-active properties of ammonia are in many ways similar to those of the organic amines. This makes it possible to consider ammonia as a model ligand, which electrochemical behaviour can be extended to the entire family of other complex-forming agents.

A typical representative of the anion-type ligand is pyrophosphate-ion $\left(\mathrm{P}_{2} \mathrm{O}_{7}{ }^{4-}\right)$. Like ammonia ligands, they are often used in industrial plating processes, therefore it was also chosen for our research.

Table 1

Composition of waste water model solutions studied

\begin{tabular}{|c|c|c|c|c|c|}
\hline \multirow{2}{*}{$\begin{array}{c}\text { Waste waters } \\
\text { model solutions }\end{array}$} & \multirow{2}{*}{ Components } & \multicolumn{4}{|c|}{ Concentrations, g/l } \\
\cline { 3 - 6 } & & $\mathbf{1}$ & $\mathbf{2}$ & $\mathbf{3}$ & $\mathbf{4}$ \\
\hline \multirow{2}{*}{$\mathrm{Zn- \text {containing }}$} & $\mathrm{ZnSO}_{4}$ & 0,01 & 0,01 & 0,01 & 0,1 \\
& $\mathrm{NH}_{4} \mathrm{Cl}$ & - & 0,01 & 0,1 & 0,024 \\
\hline \multirow{2}{*}{$\mathrm{Ni}$ - containing } & $\mathrm{NiSO}_{4}$ & 0,01 & 0,01 & 0,01 & 0,01 \\
& $\mathrm{NH}_{4} \mathrm{Cl}$ & - & 0,004 & 0,01 & 0,1 \\
\hline \multirow{2}{*}{$\mathrm{Cu}$-containing } & $\mathrm{CuSO}_{4}$ & 0,01 & 0,01 & 0,01 & 0,01 \\
& $\mathrm{Na}_{4} \mathrm{P}_{2} \mathrm{O}_{7}$ & - & 0,01 & 0,1 & 0,156 \\
\hline \multirow{2}{*}{$\mathrm{Cr}$ - containing } & $\mathrm{CrO}_{3}$ & 0,01 & - & - & - \\
& $\mathrm{CrCl}_{3}$ & - & 0,01 & - & - \\
\hline
\end{tabular}

Electrochemical behaviour of heavy metal containing model waste water solutions was studied on the base of potentiodynamic polarization curves - PDPC. The curves were registered using the P-5827 potentiostate and the PDPI-002 potentiometer in the commercial glass electrolytic cell, in which the anodic and cathodic compartments were separated with the porous glass partition. The potential elevation rate $(2$ and $10 \mathrm{mV} / \mathrm{s})$ was selected in such a way that the first regime made it possible to register PDPC in the regime close to the stationary electrolysis, while the second one - made it possible to estimate the influence of concentration limitations on the electrode process. The electrode potentials were measured with regards to the saturated chlorine-silver electrode.

The cathodic PDPC were registered on iron (Armko-Fe), copper and nickel electrodes, the anodic ones - on iron and aluminium, in order to receive the results under the conditions close to the electrocoagulation treatment of waste waters.

The PDPCs were registered with the strictly fixed position of the Luggin-Gaber capillary to exclude the resistance of the solution layer between the electrode surface and capillary.

\section{Results and discussion}

Some data related to the $\mathrm{Zn}$ behaviour in acid ammonium chloride solutions are given in the work [9]. According to our results (Fig.1), all the potentio-dynamic polarization curves (PDPC) registered on iron electrode in the simulated zinc-containing ammonium-free galvanic waste waters, are characterized by the presence of two portions:

1) Initial portion with low values of electrode potential, with low slope with regard to the potentials' axis, and

2) A sharper portion, ascending and laying within the more negative potentials area. 


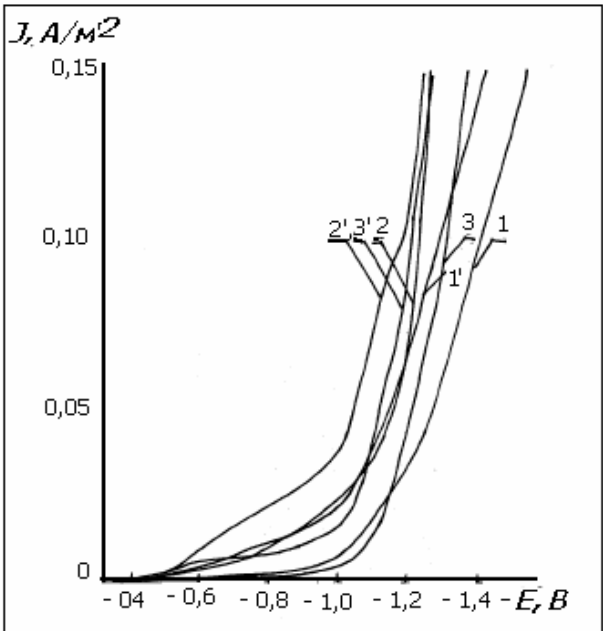

Fig. 1. Cathode PDPC of Fe-electrode in the solution of $\mathrm{Zn}(\mathrm{II})$ ions - 0,01 g/l at pH: 1, 1' - 6,1; 2, 2' - 8,1; 3, 3' - 10. Potential sweep speed, $\mathrm{mV} / \mathrm{s}: 1,2,3,-2 ; 1$ ', 2', 3' - 10 .

The initial portion of cathode PDPC is corresponding to the predominant evolving of hydrogen and gradual covering of iron electrode surface with zinc, which can result in the growth of hydrogen evolving overpotential, compared to the iron cathode, not covered with zinc.

On the ascending portion of PDPC the hydrogen evolving is mainly proceeding, causing the alkalization of by-electrode layer up to $\mathrm{pH}$ 9-10 and higher. In our experiments, the cathodic compartment was separated from the anodic one with the porous glass partition.

At the same time, with faster potential reaming $(10 \mathrm{mV} / \mathrm{s})$, PDPC are shifted to more positive potential area.

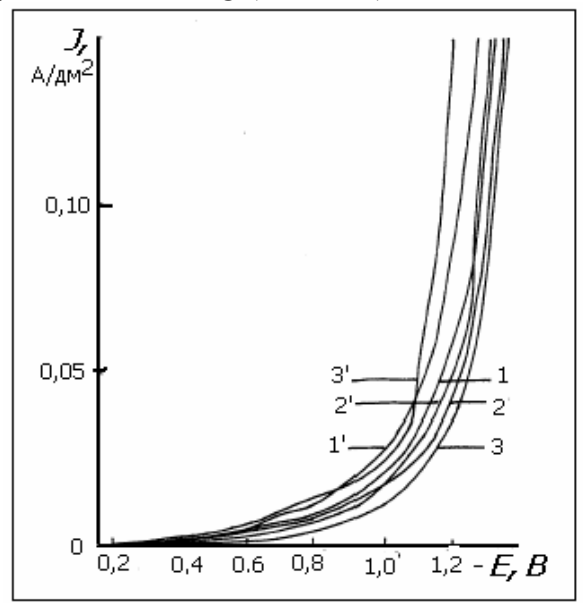

Fig. 2. Cathode potentiodynamic polarization curves of $\mathrm{Ni}$-electrode in the solution (g/l) of $\mathrm{Zn}(\mathrm{II})-0,01$

and $\mathrm{NH}_{4} \mathrm{Cl}-0,024$ under pH: 1,1 ' $-6,5 ; 2,2,-8,0 ; 3,3$ ' -10 .

Potentials sweep speed, $\mathrm{mV} / \mathrm{s}: 1,2,3,-2 ; 1,2,, 3$ ' -10 .

Such result may be explained by two reasons: 1) acceleration of protons donor reducing on cathode in comparison with the zinc (II) complexes reducing, and 2) lower size of zinc-coated cathode surface and easing of hydrogen evolving on the zinc-free surface of iron electrode, as the hydrogen evolving overpotential on this metal is lower than on zinc surface.

According to the PDPC's obtained, the influence of model solution's pH seems to be more complicated. With the $\mathrm{pH}$ growth, no shifting of curves was observed towards any potential area, as soon as the curves 2 and 2 ' are not placed between the appropriate curves 1,3 and 1'3'. Apparently, this is connected with the change in chemical composition of both zinc donors and hydrogen donors during their reduction on the cathode. It is to be noted that there are two limited currents plateaus PDPC (curve 2'). At the same time, the shift of this curve, and also of curve 2 is observed, towards the more positive potentials area, more than the shift of all the other PDPC. Perhaps, such a result is associated with the low concentration of electrochemically active $\mathrm{Zn}$ (II) compounds under $\mathrm{pH} 8,1$ in the model solution (presence of limiting current portions on PDPC 2'), which causes higher iron electrode surface uncovered with zinc, hydrogen evolving and significant alkalization of by-cathode layer. The latter fact should provoke the change in the nature of proton donor in the cathode reaction: water molecules instead of hydroxonium ions. 
The research of electrochemical behavior of zinc-containing model solutions with the contents in ammonium chloride (Fig.2), carried out on Ni electrode under various $\mathrm{pH}$ with various potentials sweep speed, has shown that the polarization curves are placed within the same potentials area as those obtained in the model solution with no ammonium ions. However, the potential of electrode to which no voltage is applied, in the ammonium-free solution is shifted to more positive area (by about $1 \mathrm{mV}$ ). By their form, these cathode PDPC are distinguished with that the initial portions of curves for different $\mathrm{pH}$ values are grouped in a more compact way. The lower dispersion is observed for the ascending PDPC branches. These insignificant differences can be attributed to the effect of electrode material $(\mathrm{Ni})$ and the involvement of ammonium ions, equally with zinc complexes and proton donors, in the formation of double electric layer.

Therefore, formation of zinc (II) complexes with ammonia in water solutions starts under the lower $\mathrm{pH}$ values $(5,0)$, than the formation of its hydroxides ( $\mathrm{pH} 9,7)$. In dependence on $\mathrm{Zn}^{2+}$ ions and ammonia concentrations ratio under the various $\mathrm{pH}$, the following zinc ammonia complexes may be present in waste waters, with the appropriate instability constants: $\left[\mathrm{Zn}\left(\mathrm{NH}_{3}\right)\right]^{2+}\left(4,26.10^{-3}\right) ;\left[\mathrm{Zn}\left(\mathrm{NH}_{3}\right)_{2}\right]^{2+}\left(1,54.10^{-5}\right) ;\left[\mathrm{Zn}\left(\mathrm{NH}_{3}\right)_{3}\right]^{2+}\left(4,87.10^{-8}\right) ;\left[\mathrm{Zn}^{2}\left(\mathrm{NH}_{3}\right)_{4}\right]^{2+}$ $\left(3,46.10^{-10}\right) ;\left[\mathrm{Zn}\left(\mathrm{NH}_{3}\right)_{5}\right]^{2+}$ (in very low concentration) and $\left[\mathrm{Zn}\left(\mathrm{NH}_{3}\right)_{6}\right]^{2+}$, existing within very broad $\mathrm{pH}$ area (from 8 up to 13 and higher).

Ammonia complexes with higher coordination number, exist outside the limits of zinc hydroxides formation $\mathrm{pH}(\mathrm{pH}=12)$. All of them are water soluble and will remain in solution after the alkaline treatment of zinc-containing waste waters, and also after the electrocoagulation treatment of such waters. So, the alkaline treatment of such type of waste waters in view to remove heavy metal would be inefficient, as during this treatment, equally with zinc (II) ammonia complexes, the anion-type hydroxide complexes $\mathrm{Zn}(\mathrm{OH})_{3}{ }^{-}$and $\mathrm{Zn}(\mathrm{OH})_{4}{ }^{2-}$ will be present in water solution, due to the amphoteric character of zinc hydroxide. This testifies that with using the above-mentioned treatment methods, the satisfactory removal of zinc from $\mathrm{Zn}$-containing waste waters cannot be reached.

Fig. 3A shows the cathode PDPC obtained in the ammonia-free model solutions. The curves, as in the case of zinc-containing solutions, have initial and ascending branches. The initial branch is thus characterized by the presence of limiting current, which can be attributed to the cathodic process of nickel aqua-complexes reducing, masked by the reduction of protons donors. This conclusion is based on the low value of hydrogen overvoltage on iron surface. With the $\mathrm{pH}$ increase, polarization curves are shifted to more negative potentials, due to the involvement in electrode reaction of the available and newly forming nickel (II) hydroxocomplexes, under the higher $\mathrm{pH}$ in the by-electrode layer.
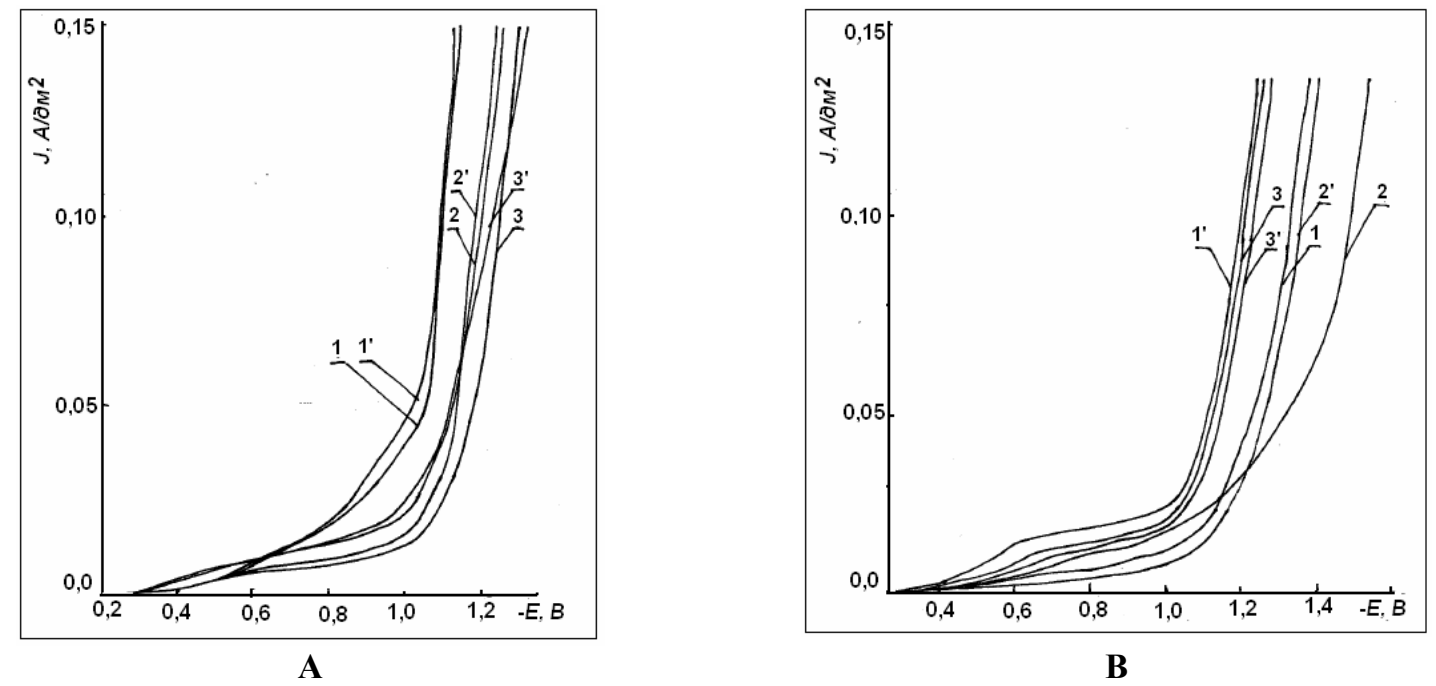

Fig. 3. Cathode potentiodynamic polarization curves of Fe-electrode in the solutions, containing $(\mathrm{g} / \mathrm{l})$ : $\mathrm{Ni}(\mathrm{II})-0,01$ (A); $\mathrm{Ni}(\mathrm{II})-0,01$ and $\mathrm{NH}_{4} \mathrm{Cl}-0,0037$ (B) under $\mathrm{pH}$ : 1, 1'-6,15; 2, 2'-8,1; 3, 3'-9,95. Potentials sweep speed, $\mathrm{mV} / \mathrm{s}: 1,2,3,-2 ; 1^{\prime}, 2^{\prime}, 3^{\prime}-10$.

Presence of ammonia ions in model solutions and their effect on the cathode process, in the case of iron electrode, is illustrated by Fig.3B. The higher value of limiting current for the initial PDPC portions is explained by two factors: 1) catalytic effect of labile protons donors, adsorbed on the negatively charged surface of iron electrode and 2) proton-donor and buffer effect of ammonium ions, which to some degree prevent alkalinization of by-cathode layer. We should note that the effect of ammonium ions is most clearly shown on the initial PDPC portions and in the model solutions with lower $\mathrm{pH}$ values $(6,5)$, where their buffering role is most clearly pronounced.

As follows from Fig.4, the portions of limited diffusion current with respect to copper ions are clearly shown on PDPC obtained in copper sulphate solution. As could be expected, with the increase of potentials sweep speed, PDPC are slightly shifted to more positive area. The data presented demonstrate that the electrochemical method can be successfully applied for the pre-treatment of the galvanic copper-containing waste waters for the elimination of copper ions. 


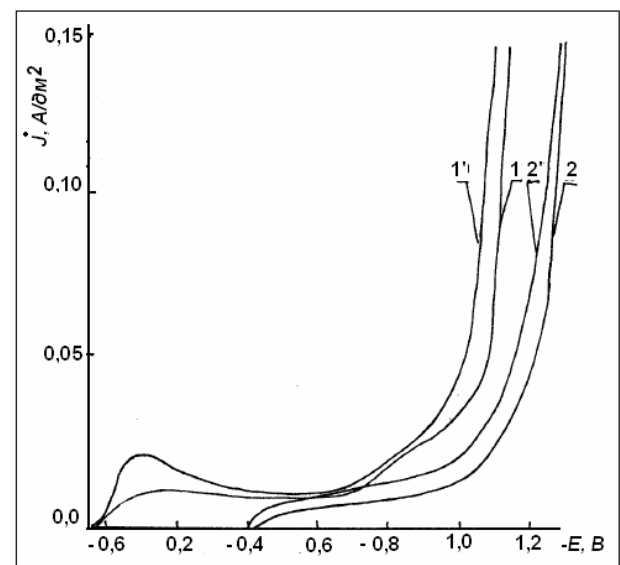

Fig. 4. Cathodic PDPC of Ni-electrode $\left(1,1^{\prime}\right)$ and Fe -electrode $\left(2,2^{\prime}\right)$ in $0,01 \mathrm{~g} / \mathrm{l} \mathrm{Cu}(\mathrm{II})$ solution under $\mathrm{pH}=5,3$ and potentials sweep speed, $\mathrm{mV} / \mathrm{s}$ : 1,2 - 2; 1', 2' - 10 .

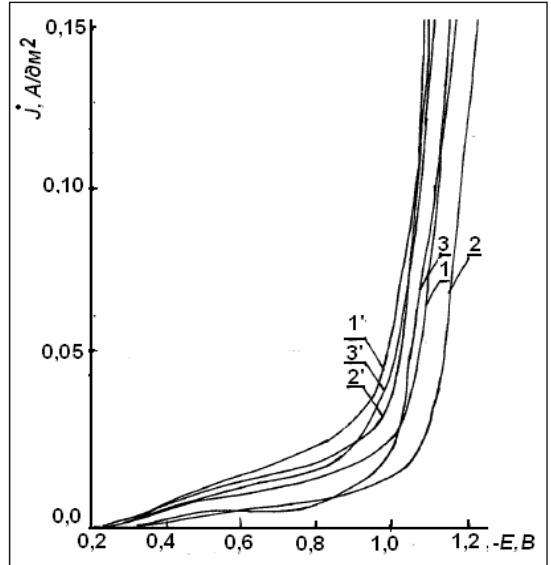

Fig. 5. Cathodic PDPC of Fe - electrode in the solution of ions (g/l): $\mathrm{Cu}(\mathrm{II})-0,01$ and $\mathrm{Na}_{4} \mathrm{P}_{2} \mathrm{O}_{7}-0,1566$ under $\mathrm{pH}: 1,1^{\prime}-5,8$;

2, 2'-8,2; 3, 3'-10. Potentials sweep speed, $\mathrm{mV} / \mathrm{s}: 1,2,3,-2 ; 1$ ', 2', 3' - 10.

With the decrease in copper ions concentration in by-electrode layer, an increase in current density is observed as a result of the beginning of another cathodic reaction - electrochemical reducing of proton donors with hydrogen evolving on electrode [10]. The overvoltage growth is thus connected with copper, which covers the surface of nickel and iron electrode.

Electrochemical behaviour of copper in pyrophosphate-containing solutions was studied on iron electrode (Fig. 5). Polarization curves, like in previous cases, are characterized with the initial and ascending portions, although they are shifted to about $200 \mathrm{mV}$ in the negative potentials area, compared to the PDPC obtained in the model solutions of acid copper electrolytes. The limiting current is not fixed here in most cases, whereas the smooth ascending of PDPC initial branch is specific.

Thus, at less negative potentials, copper (II) complexes with pyrophosphate-ions having less negative charge, should participate in the cathode reaction. With the by-electrode layer depletion as regards to copper complexes $\left[\mathrm{Cu}\left(\mathrm{P}_{2} \mathrm{O}_{7}\right)^{2-}\right]$, electrode potential and its surface charge becomes more negative. Under these conditions, the cations of alkali elements or hydroxonium ions are mainly adsorbed on the cathode surface. They play the role of cation bridges, which ease the formation of transition state (surface complex) on copper-covered iron electrode surface with participation of both above-mentioned complexes and $\left.\mathrm{Cu}\left(\mathrm{P}_{2} \mathrm{O}_{7}\right)_{2}\right]^{6-}$. The cathodic reaction potential will be thus shifted to the more negative values, and PDPC elevation becomes sharper.

At the ascending PDPC branch both the reactions of electrochemical reduction of copper pyrophosphate complexes occur, along with the process of proton donors reduction. The effect of the potentials elevation rate is similar to the previous case (Fig. 4).

Special attention should be paid to the effect of $\mathrm{pH}$ of pyrophosphate-containing model solution on its electrochemical behaviour.

Fig. 5, at first glance, gives no possibility to discern the strict regularities in $\mathrm{pH}$ effect on the cathodic process: PDPC are intersecting with each other many times. The curves obtained in more alkaline solutions $(\mathrm{pH}=8,2)$, are sometimes in more positive potentials area. It should be considered however, that the conditions of cathodic reactions are determined not only and not so much by $\mathrm{pH}$ in the bulk of solution, but sooner the $\mathrm{pH}$ value in the by-electrode zone. It could be concluded that it is factor that determines the electrochemical behaviour of pyrophosphatecontaining model solutions of plating waste waters (used copper electrolytes). The change in the ration of copper (II) complexes cathodic reduction rates and proton donors reduction $\left(\mathrm{H}_{3} \mathrm{O}^{+}, \mathrm{H}_{2} \mathrm{O}, \mathrm{H}_{4} \mathrm{P}_{2} \mathrm{O}_{7}, \mathrm{H}_{3} \mathrm{P}_{2} \mathrm{O}_{7}, \mathrm{H}_{2} \mathrm{P}_{2} \mathrm{O}_{7}{ }^{2-}, \mathrm{HP}_{2} \mathrm{O}_{7}^{3-}\right)$ will, accordingly, modify the $\mathrm{pH}$ of by-cathode layer.

PDPC registered in model solutions of $\mathrm{Cr}$ (VI)-containing industrial waste waters on different electrodes (Fig.6) show the step-by-step electrochemical reduction of chromium compounds. There are four portions and two clearly expressed limiting currents on these curves.

The initial portion with low inclination angle is related to the reduction of chromate-ions up to the nearest intermediate oxidation degree of $\mathrm{Cr}$ with the involvement of labile protons, playing the role of electron bridges. Starting from $-0,8 \mathrm{~B}$, the most probably, proceeds the formation and reduction of $\mathrm{Cr}$ (III) to $\mathrm{Cr}$ (II). The ascending PDPC branch in the area of $-1,2 \mathrm{~V}$ can be attributed to the joint reduction of proton donors and cationic forms of $\mathrm{Cr}$ (III) aquacomplexes and $\mathrm{Cr}$ (II) to $\mathrm{Cr}^{0}$. The similar course is specific for PDPC of chromate-ions reduction on cathode from model solution on Ni-electrode (Fig. 6B). 

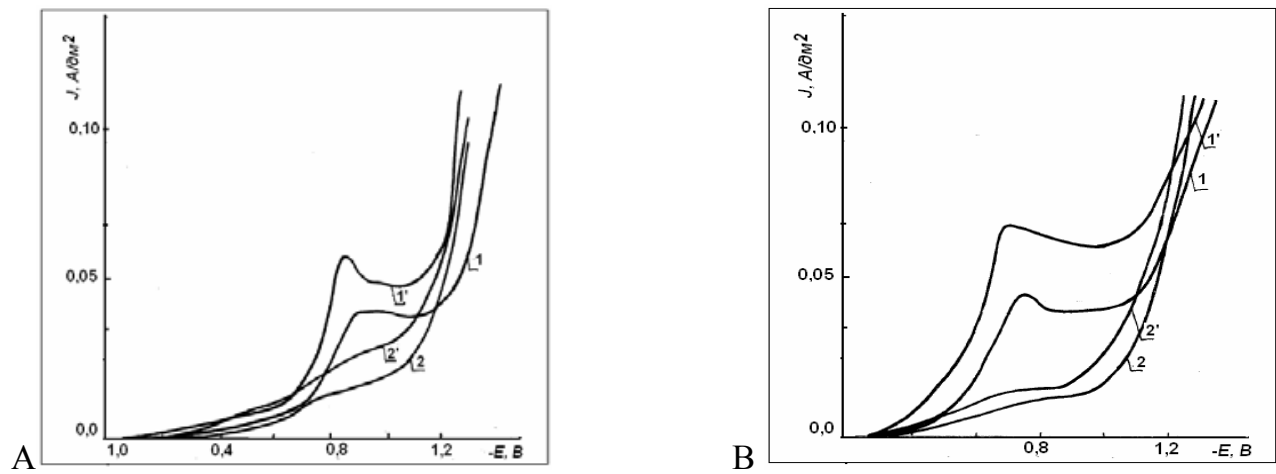

Fig. 6. Cathodic PDPC Cu-electrode (A) and Ni-electrode (B) in the solution of $\mathrm{Cr}(\mathrm{VI})-0,01 \mathrm{~g} / \mathrm{l}$ under pH: 1, 1' - 2,8; 2, 2' - 4,8. Potentials sweep speed, $\mathrm{mV} / \mathrm{s}: 1,2$ - 2; 1', 2' - 10.

The following conclusions can be made on the basis of data obtained. Chromium compounds in soluble state can exist equally in acid and neutral and alkaline solutions. The oxidation degree of chromium during the electrochemical treatment can be varied from $\mathrm{Cr}(\mathrm{VI})$ to $\mathrm{Cr}^{0}$.

The specifics of chromium complexes behaviour in acid solutions is interesting from the viewpoint of $\mathrm{Cr}$ (III) ions removal from them. Thus, when the alkaline-chemical treatment is applied to obtain $\mathrm{Cr}(\mathrm{OH})_{3}$ hydroxide, it should be taken into account that hydrato-formation reaction proceeds with time. $\mathrm{Cr}$ (III) polynuclear aquahydroxocomplexes can be destroyed with difficulty. Besides, chromium hydroxides formed with time are becoming less and less easily dissolvable, due to the transformation to polynuclear forms. "Ageing" of heavy metal hydroxides with time is known for a long time [11].

The amphoteric character of $\mathrm{Cr}$ (III) hydroxide and its transformation in soluble anionic hydroxycomplexes should be considered, as well. Such transformation of polymerized ("inveterate") hydroxides also proceeds with time.

Therefore, the alkaline treatment of $\mathrm{Cr}(\mathrm{III})$ - and $\mathrm{Cr}(\mathrm{VI})$-containing galvanical waste waters treatment is rather problematic and cannot be recommended for practical uses. Removal of $\mathrm{Cr}$ from used solutions requires the application of oxidation-reduction methods combined with the pre-treatment, or using of the appropriate selective sorption methods, or other modern treatment methods, among them electrocoagulation with soluble Fe-electrodes.

\section{Conclusion}

Based on the study of electrochemical behaviour of some $d$-metal with amphoteric properties $\left(\mathrm{Zn}^{2+}, \mathrm{Ni}^{2+}\right.$, $\mathrm{Cu}^{2+}, \mathrm{Cr}(\mathrm{VI})$ and $\mathrm{Cr}^{3+}$ ) complexes with ammonia and pyrophosphate ligands under the low concentrations in water solutions within the broad $\mathrm{pH}$ range, it was shown a complex approach is required to provide the efficient metal removal from such waste waters. As the chemical alkaline treatment for such low-concentrated solutions with the scope to obtain insoluble products which can be separated, would be unacceptable, the electrochemical approach was proposed for the removal of metal ions.

Therefore, it may be recommended to apply the electrochemical method of metal deposition on flow-through carbon fibre cathode. Such electrodes possess high specific surface, which makes it possible to provide the selective deposition of metals under the energy-saving conditions, due to the low specific current densities applied, corresponding to the potential of metal deposition [12].

\section{References}

[1]. Juttner, K., Galla, U., Schmieder, H. Electrochemical approaches to environmental problems in the process industry. Electrochimica Acta, Vol.45, Is.15-16 May 2000; pp. 2575-2594.

[2]. Vinogradov S.S. Ecologically safe plating industry/ Ed. V.N. Kudeavtsev. Moscow: Globus, $2002 ; 352$ p.

[3]. Vysomirskis, R.M. Kinetics of Metal Plating from Complex Electrolytes. Moscow: Nauka, 1969; 244 p.

[4]. European Committee for Surface Treatment. "Surface Treatment of metals and plastic materials using electrolytic or chemical process". Reference Document on best available techniques for Integrated Pollution Prevention Control (IPPC). June, 2001, 69p.

[5]. Kozin, L.F. Electrodeposition and Dissolving of Polyvalent Metals. Kiev: Naukova Dumka, 1989; 464 p.

[6]. Popov, K.I., Djokic, S., Grgur, B. Fundamental Aspects of Electrometallurgy. Springer US, 2002; pp. $191-196$.

[7]. Antropov, L.I. Theoretical Electrochemistry. Moscow: Vysshaia Shkola, 1984; 520 p.

[8]. Frumkin, A.M., Bagotzky, V.S., Iofa, Z.A., and Kabanov, B.N. Kinetics of Electrode Processes. Moscow: Izd.Mosk.Univ., 1952; 336 p.

[9]. Shishkina S.V., Maslenikova I Yu. Electrodialysis of Solutions Simulating Water in Rinsing Tanks after Zinc Plating from Weak-Acid Ammonium Chloride Baths / Electroplating \& Surface Treatment, VI., nr.3, 1998, pp. 41-46.

[10]. Khobotova, E.B., Zaretchenski, V.M. Regeneration of Rinse Water Containing Copper and Ammonia. Electroplating \& Surface Treatment, V.3, 1997; pp 43-49.

[11]. Yakovlev, S.V., Volkov, L.S., Voronov, Yu.V., Volkov, V.L. Treatment and utilization of solid wastes from the industrial waste waters. Moscow: Khimia, 1999; 448 p.

[12]. Maslyi, A.I., Medvedev, A.J., Poddubnyi, N.P. Dynamics of copper electro-deposition on the flow-through porous electrode. Electrochemistry, Vol.41, Nr.11, 2005; pp.1335-1339. 